\title{
The Development of the Ethics Textbooks in China Since the Reform and Opening-up
}

\author{
Liu Ang ${ }^{1}$, Yang Weirong ${ }^{2, ~ * ~}$ \\ ${ }^{1}$ Marxist College of Nanjing Normal University, Nanjing, China \\ ${ }^{2}$ Department of Philosophy, School of Public Management, Nanjing Normal University, Nanjing, China
}

Email address:

Yangweirong121@qq.com (Yang Weirong)

${ }^{*}$ Corresponding author

To cite this article:

Liu Ang, Yang Weirong. The Development of the Ethics Textbooks in China Since the Reform and Opening-up. International Journal of Philosophy. Vol. 7, No. 1, 2019, pp. 41-47. doi: 10.11648/j.ijp.20190701.16

Received: January 5, 2019; Accepted: February 28, 2019; Published: March 20, 2019

\begin{abstract}
The development of ethics as an independent discipline is inseparable from the continuous improvement of teaching materials, and ethics textbooks are an important carrier of ethics learning. In the historical process of China's 40 years of reform and opening up, the development of ethics textbooks has experienced three important historical stages: beginning, perfection and maturity. In this process, with the guidance of Marxism, the author keeps on promoting the main theme, and discusses in detail the ethical research object and its essence, the history of Chinese and foreign ethical thoughts, moral structure, applied ethics and the development prospects of ethics, which greatly promoted The advancement of ethics throughout the discipline also reminds researchers of the future of ethics. However, there is still room for further improvement in the form of expression, rationale, and practice of the textbook. In view of this, the construction of ethics textbooks must inherit the Chinese excellent traditional culture with the "compatibility and integration of diverse positions and methods", absorb the reasonable content of Western culture, innovate the expression of teaching materials, focus on the theoretical logic, pay attention to the reality of life, and let ethics enter life. To enhance the acceptability, scientificity and practicality of the textbook.
\end{abstract}

Keywords: The Reform and Opening-up, Ethics Textbooks, Development Overview

\section{The Basic Process and Characteristics of the Construction of Ethics Textbooks Since the Reform and Opening-up}

As a country with thousands of years of historical and cultural heritage, China has broad and profound ethical thoughts. However, ethics as an independent discipline began from the early 20th century. Ethics Textbook, which was marked the official production of the ethics discipline was compiled by Liu Shipei and published in 1906. However, due to the war in modern China and the special political environment after the founding of the People's Republic, the discipline of ethics was almost died. In the late 20th century, in order to meet the needs of the reform and opening-up as well as the modernization strategy, the construction of this discipline and its teaching material was restarted.

\subsection{Based on the Local and Learn from the Soviet Union: The Initial Stage of the Construction of Ethics Textbooks (1978-1991)}

"Chinese ethics has developed into a new stage since the reform and opening-up" [1]. In 1978, Renmin University of China took the lead in reopening the ethics course across the country. In the following year, it resumed the ethics teaching and research section established in the early 1960s and started normal ethics teaching and research activities. Peking University, Beijing Normal University, East China Normal University, Chinese Academy of Social Sciences as well as other universities and research institutes have also opened ethical courses and established ethical teaching and research sections. In addition, the State Education Commission also entrusted Renmin University of China to hold a national training course for ethics teachers in universities in the early 1980s. The training course was held for two sessions. There 
were nearly 80 participants attend the training, which laid talent base for the restoration and prosperity of ethics after the reform and opening-up. On this basis, Renmin University of China established the first Ph.D. in the second-level discipline of ethics across the country in 1984, which became an important base for ethics training.

In order to meet the needs of ethics teaching and research, a large number of ethics researchers began to focus on the writing and revision of textbooks. Facing the lack of theoretical resources in ethics, the researchers represented by Luo Guojie turned their attention to the Soviet Union. Studying the Marxist ethics of this neighboring country and combining them with our national conditions, they edited and published the first textbook of Marxist ethics in China since the reform and opening-up. It was named Marxist Ethics, which marked the beginning of the construction of ethics textbooks in China. Subsequently, Luo Guojie organized and compiled textbooks such as The Course of Ethics and Ethics. These textbooks laid the foundation for the general direction of the construction of ethics textbooks in China. At the same time, Tang Kailin edited Concise Marxist Ethics and Ethics Outline; Bao Lianzong and Zhu Yiting edited Introduction to ethics; Zhou Yuanbing edited Common Theory of Communism; Zhang Haishan edited Concise Ethics; Xiao Xuehui edited Ethics Principles; Wei Daoli edited Ethics (Revised); Chen Yu and Liao Shenbai edited Modern Ethics; Wang Xiaoxi and Guo Guangyin edited General Theory of Ethics; Starting from the specific theory of Marxism and based on the textbooks of Soviet ethics, all these textbooks construct the basic framework of Chinese ethics textbooks.

\subsection{Focus on Reality and Enrich Contents: The Development Stage of Ethics Textbook Construction (1992-2000)}

Deng Xiaoping's southern talks and the establishment of a socialist market economic system have brought China's reform, opening-up, and socialist modernization into a new historical period. It injected a new era connotation and realistic foundation for the construction of ethics textbooks in China. In this period, the construction of ethics textbooks "appears adaptation to the requirements of the times and social development, renewal of theoretical system and facing to the market economy as a new image of the theory on the academic arena in China" [2]. It paid more attention to reality and constantly enriched itself according to the change and development of practice. Tang Kailin edited Ethics Course; Gan Yilu and Tang Kailin edited Ethics Principles; Wang Xiaoxi edited Ethics Research Outline; Wei Yingmin edited New Ethics Course; Wan Junren edited New Theory of Ethics; Zhang Haishan edited Introduction to Ethics; Jiang Chang edited Theoretical Ethics; All these textbooks were set against the requirements of the new era. They integrated the economic foundation of the socialist market economic system into them, which enriched the contents of ethics textbooks.

\subsection{Conform to the Trend and Hold the Direction: The Mature Stage of the Construction of Ethics Textbooks (2001-Present)}

Since the new century, Chinese ethics has made great progress. The Research Center for Ethics and Moral Construction in Renmin University of China and the Research Center for Moral Culture in Hunan Normal University have been assessed as the key research base for humanities and social sciences by the Ministry of Education. At the same time, in recent years, the number of ethics doctoral and master's degree programs in universities and research institutes in China has been increased. The number and quality of ethics graduate students have also been improved significantly. With the development of the ethical discipline, the construction of ethics textbooks in China is closely following the trend of the times. It firmly grasps the research direction of Marxism and constantly revises textbooks. Yu Yaping edited Ethics; Zhou Zhongzhi edited Ethics; Wang Haiming edited Ethics Principles (third Edition); Liao Shenbai edited Introduction to Ethics; Zhang Yinghang edited Introduction to Ethics; Zhang Xiaoping edited New Ethics; Wei Yingmin edited New Ethics Course (Third Edition); Wang Zeying edited Ethics; Whether in content arrangement or in forms, these books adhere to the guidance of Marxism. They fully reflect the current era connotation. Moreover, the Central Committee of the Communist Party of China Marxist theoretical research and construction project also edited the textbook of Ethics. "This is a textbook that was written by the latest achievements of Marxism and sinicization of Marxism. It is a master work that reflects the latest achievements in the sinicization of marxist ethics" [3].

\section{Major Achievements in the Construction of Ethics Textbooks}

In the past 40 years of reform and opening-up, it has been a golden period for the construction of ethics textbooks. In this period, the construction of textbooks has been closely related to the main theme and adhered to the guidance of Marxism. It makes the construction of the ethical textbook system more reasonable and the content of the textbook more plentiful.

\subsection{Carry Forward the Main Theme and Adhere to the Guidance of Marxism}

Since the reform and opening-up strategy made by the Third Plenary Session of the Eleventh Central Committee of the Party in 1978, our science, education, culture and medical undertakings have faced unprecedented opportunities. As an old and emerging discipline, ethics needs reforms to overcome existing drawbacks and accept the new trend of thought. Based on this background, the construction of teaching materials as a guiding direction for the development of the discipline is particularly important.

During this period, various western social trends continued to flow into China. It affected people's value judgments and 
behavior choices. Facing this reality, the construction of ethics textbooks in China has always firmly grasped the main theme and insisted on the guidance of Marxism. It is convinced that only under the guidance of Marxism ethics can keep up with the current of times and grasp the essence rule. A large number of ethics textbooks that adhere to the direction of Marxism and adopt the research methods of dialectical materialism and historical materialism are constantly coming out. Their analysis of morality "not only excludes the moral interpretation of religious mysticism, but also avoids various forms of moral subjective voluntarism, subjectivism and moral relativism. It places an objective and effective social foundation for morality" [4]. And it firmly grasped the main theme.

\subsection{Maturity of System Construction and Rational of Structure}

Since the reform and opening-up, the ethics textbooks have basically established the research object, research content, research nature, the starting point and ultimate purpose of the ethics. Ethics are roughly classified to highlight the special status of ethics as a moral subject and the ethics system are constantly improved. After more than 30 years of development, the construction of ethics textbooks in China has basically constructed a set of theoretical systems with clear thinking and logic which gets rid of the previous scattered and isolated fragmented state.

Judging from the structural arrangement of ethics textbooks, they have paid more attention to knowledge and humanity design since the reform and opening-up. In this period, most ethics textbooks started with the relationship between ethics and morality and explained the origin, essence, structure, function, principle, norms, basic categories, operational mechanism, historical development and rule of morality. They construct scientific and reasonable contemporary ethical standards and requirements to help the moral subject to establish a correct outlook on life and develop a good moral quality and moral cultivation. Therefore, they can make appropriate moral behavior and evaluation. On this basis, the importance of moral education, moral communication and moral construction is emphasized. At the same time, the ethics textbooks of the new century have also increased the applied ethics section. In addition, some ethics textbooks start with the development of Chinese and foreign ethics. They explained meta-ethics, normative ethics, and virtue ethics respectively. Generally speaking, the ethics textbooks have become more rational in terms of structural arrangement and avoid the rigid stereotypes since the reform and opening-up. They become more logical and acceptable in knowledge.

\subsection{Constantly Enriching Teaching Materials}

The construction of ethics textbooks has entered a new historical period since the $1980 \mathrm{~s}$. The ethics textbooks at this stage mainly involve ethical research objects and their essence, Chinese and foreign ethical thought history, moral structure, applied ethics, ethical development prospects and so on.

\subsubsection{The Object of Ethics Research and Its Essence}

Since the reform and opening-up, the basic categories of ethics in textbooks have mainly focused on the research objects and their essence. The general textbooks believe that, "Ethics is a science of morality. In other words, ethics is a science in which morality is its own research object" [5]. On this basis, some textbooks specifically consider, "Ethics is a subject that study moral issues and teach people how to behave" [6]. Some textbooks say, "Ethics takes moral phenomena as its own research object... Ethics is a philosophical science branch that refers to the most general revelation of moral phenomena and their laws of existence and development" [7]. Unlike this, there are some other textbooks considered that, "Ethics is a science of good moral or moral values. It means that ethics is a normative science or a value science rather than a scientific or factual science" [8]. In addition, there are also textbooks considered that, "Ethics faces human problems. It is a special study of human problems" [9]. Thus, whether ethics studies moral issues, a moral phenomenon or a moral value, the ultimate goal is morality. Even when it comes to people, it comes to people's morality. It is not difficult to find that ethics and morality are closely related. Then, what is morality or the essence of morality, different textbooks also give different answers.

The first ethics textbook after the reform and opening-up is based on the point of Marxism. It believes that, "morality is unique to human social life. It is determined by economic relations. It depends on people's inner beliefs and special social means. It is the sum of principles, norms, psychological consciousness and behavior activities that are evaluated by good and evil" [10]. At the same time, some textbooks add the special essence of morality on this basis. It believes that, "Morality is the unity of social ideology and human's practical spirit to real society" [11]. There are also textbooks starting from 'humanity and morality' and thinking that "Moral is a special society that based on the subjective nature of human nature and arise from objective social relations" [12]. There are also some textbooks based on the comparison between morality and law, rules and ethics. It is said that "ethics is a non-power norm that is formulated or recognized by society which has socially useful behaviors" [13]. From the perspective of etymology, some textbooks test the emergence of the Chinese and Western word "morality" and think, "Ethics is a good thing that belongs to oneself. Especially it is the excellent quality of practical affairs but not the added good things. At the same time, morality is also a thing that one asks for oneself from the heart. That is the inner principle not the external requirements" [14]. The study of the definition and essence of morality has always been a hot topic of academic research. Today, the authoritative view of this issue is that morality is determined by the economic foundation. It takes right and wrong, good and evil as the evaluation standard. It depends on traditional customs, public opinion and inner beliefs to adjust the relationship between human and nature and it is the sum of activities that related to the concept and behavior [15]. 


\subsubsection{History of Chinese and Foreign Ethics}

The history of Chinese and foreign ethical thoughts is the development of ethics. It occupies an important position in ethics textbooks. After the reform and opening-up, most of the textbooks sorted out Chinese, Western and Marxist ethical thoughts systematically and comprehensively. There are researches on a certain period of time, ideas of the main characters, and an overview of the development of major schools.

Most of the textbooks adopt the method of installment to study Chinese traditional ethical thoughts. Some are divided into four periods of "Spring and Autumn Warring States, Qin and Han Dynasties, Song and Yuan Dynasties and Modern Bourgeoisie" [16]. And some others are divided into "Spring and Autumn Warring States, Qin han to Qing dynasty and the end of the Qing Dynasty to the May Fourth Movement" [17]. Different from the way of using historical staging, some textbooks logically examine the development of ethical thoughts according to the main viewpoints of different genres. It mainly explains the problem of human nature as the starting point of ancient ethics theory. It also comes up with the meaning of ancient Chinese ethical thoughts, like righteousness, desire (law), self-interest and altruism, and debate on life and death. And it shows moral rational personality (that is, the way of adulthood) as the destination of ancient ethics [18].

Regarding to the introduction of Western traditional ethical thoughts, textbooks basically divide them into three stages: the ethical thoughts of the ancient Greek and Roman slave society, the ethical thoughts of the medieval feudal society and the Renaissance to the modern bourgeois ethics [19]. It discusses its main factions and features. At the same time, some textbooks divide the development of Western ethical thought history into three major schools of "rationalism, irrationalism and trust" [20] from the perspective of the unity between history and logic. And a general comment on the thoughts of the main representatives is made.

In the process of discussing the development history of Marxist ethical thoughts, the textbook editors focus on the conditions of their formation and production. It believes that Marxist ethical thought is based on historical materialism and uses dialectics of materialism to study moral phenomena and reveal the law of moral development. It is the advanced and scientific ethical thought that take the proletarian morality, socialist morality and communist morality as the main research contents [21]. At the same time, some textbooks believe that the emergence of Marxist ethics has its objective inevitability of history. The production has its foundation of material conditions, class roots and theoretical basis [22]. In addition, there are textbooks to discuss the developmental process of Marxist ethics. It is considered that it experienced three stages of development: Marx and Engels stage, Lenin Stalin stage, Mao Zedong thought stage [23].

\subsubsection{The Structure of Morality}

As a research object of ethics, morality has a relatively stable structure among its internal components. In the past 40 years of reform and opening-up, ethics textbooks have elaborated on the moral structure and its contents. Based on this, it has constructed a scientific framework.

Some ethics textbooks divide moral structure into social moral structure and individual moral structure. Some of the textbooks believe that the social moral structure can be divided into relational structure, phenomenal structure and level structure. Individual moral structure can be divided into two forms: individual moral psychology and individual moral behavior [24]. Some textbooks divide the social moral structure into three elements: moral consciousness, moral standard and moral activity. The individual moral structure is divided into individual moral consciousness, individual moral behavior and individual moral quality [25]. At the same time, there are also textbooks that directly attribute the moral structure to three main parts: moral consciousness, moral relationship and moral activity (moral practice) [26]. Based on the moral structure, these textbooks analyze not only the content of the moral system, but also the psychological and emotional aspects of human morality. It will help moral subjects establish correct life outlook and values through moral education, moral communication and moral construction. It will also help cultivate lofty moral ideal and make reasonable moral choices. In addition, there are also textbooks that divide the moral structure into basic structure, complete structure and deep structure. It is considered that the moral structure is extremely complicated and its content and form are two-fold. Therefore, it consists of four factors - the moral value norm, the moral value judgment, the moral purpose, and the behavioral facts [27]. Then the concrete content of moral structure is interpreted from the angle of why society make moral, how the ethical behavior fact is and how good ethical behavior should be.

At the same time, some textbooks classify the existing understanding of moral structure. It points out that some thought morality is a structure composed of moral relationship, moral consciousness and moral behavior. There is a view that morality generally consists of two aspects: moral awareness and moral activities [28]. There is a opinion that moral consciousness, moral choice, and moral practice together constitute a moral structure. Some other opinions are that moral structure is divided into aggressive morality and coordinated morality. There is a view that moral structure is a system that combines ethics, common beliefs and ultimate care. There is also a view that morality is made up of ethics and moral values. Some textbooks do not have a clear structural division of morality. But they explain from concrete to abstract. They use modules of "common sense of morality to communicative ethics, from communicative ethics to philosophical ethics and good life" [29]. The moral structure and its contents are deduced and demonstrated.

\subsubsection{Applied Ethics Research and Ethical Development Prospects}

After the reform and opening-up, especially since the 1990s, the study of applied ethics in China is in the ascendant. To a certain extent, it has continuously promoted the ethics 
discipline to "discovery". Some ethics textbooks have begun to pay attention to this latest research field and described the basic situation of its research. On this basis, some ethics textbooks also consider the development prospects of ethics.

Some textbooks use special chapters to introduce the rise of applied ethics, research content, nature and characteristics of the discipline. They point out that due to the changes in human production and lifestyle brought about by the scientific and technological revolution, there exist urgent problems for ethics to explain and judge. Applied ethics came into being and formed many emerging disciplines of applied ethics [30]. On this basis, they explain economic ethics, environmental ethics, network ethics. At the same time, there are also textbooks directly from the specific ethics category. Except for explaining economic ethics, ecological ethics, bioethics, network ethics, they also define the educational ethics and analyze the basic content and the practical significance of research [31]. In addition, some textbooks put "applied ethics" on the same level as "ethics theory". Based on this, the book is divided into two parts. They elaborate on the scope of research, the main content of research, and the background of the rise on applied ethics. And they explain specific contents such as environmental ethics, economic ethics, engineering ethics, and bioethics [32].

The development of applied ethics has promoted the advancement of the entire discipline of ethics. It also reminds researchers to think about the future of ethics. The textbook titled "Where is Chinese ethics going", comprehensively sort out the development of ethics in China since the early 1980s. It points out the achievements and problems. And it proposes the reform and improvement for the real environment that socialist ethics must be guided by Marxism, go out of the study and face the social practice, and pay attention to its own research methods [33]. Some textbooks start from three angles: the theoretical orientation of modern Chinese ethical construction, the subject of the times and the new realm of socialist ethics [34]. Some textbooks reflect the ethical spirit, moral quality and the mechanism of the rise and fall of civilization through ethical reflection on modern civilization. They point out the unity of theoretical ethics, normative ethics and applied ethics, the unity of moral ethics and utilitarian ethics, and the unity of moral teleology ethics and moral instrumental ethics, which has gradually become the developmental trend of ethics [35]. Based on our normative ethics, some textbooks point out that we will strengthen the comparative study of Chinese foreign ethics, attach importance to combing and discovering Confucian ethics and expand the research field of applied ethics in the future. Then we will form a harmonious development of democracy, science, legal system and ethics. Furthermore, from the perspective of people's all-round development, they inquiry ethics and human development prospects by analyzing the human potential, human development and status, as well as human developmental directions. They point that an era of ethical prosperity and all-round human development will come soon [36].

\section{The Regret of Existing Ethics Textbooks}

In the past 40 years of reform and opening-up, ethics textbooks have made great breakthroughs in quantity and quality. However, "all things in development are imperfect" [37]. Ethics textbooks, as carriers of ethical theories, have some regrets on insufficient diversity in form, unpersuasive in content, insufficient attention to practice in research methods and case selection.

\subsection{Lack of Formal Diversity}

The lack of formal diversity is mainly manifested in the singularity of internal and external forms. Specifically, it refers to the lack of breakthroughs in the disciplinary system constructed by ethics textbooks and the lack of innovation in the teaching material carrier.

Any disciplinary system should be opened and developed. It needs to be constantly innovated with the progress of the times and discipline construction. However, Since Marxist Ethics edited by Luo Guojie which has proposed the ethical subject system, ethics textbooks in China have continued this system and constantly repaired and innovated them with few substantial breakthroughs and innovations. As a textbook, it should not be a statement of one school. It should learn widely from others' strong points [38]. Generally speaking, "the thickness or prosperity of a discipline can be manifested through the appearance and development of theoretical schools" [40]. Chinese ethics textbooks need different voices. The debates of various schools will make the problem clearer, which is benefit to the development of the discipline and improvement of students.

In addition, the textbook carrier is also one of the manifestations of textbooks. Throughout the reform and opening-up, most of China's ethics textbooks are based on paper texts. There are few multi-dimensional textbooks that use modern multimedia technology to combine elements such as text, images, audio and video. In the face of constant development, the carrier of ethics textbooks should also keep pace with the times and make full use of the latest scientific means. They should follow the pace of the times, innovate expressions and attract students' attention.

\subsection{The Non-convincing Theory}

Ethics or moral philosophy should tell people how to live and what kind of life they should choose. However, people not only need to know "should", but also need to know why they "should". Without rational thinking about "should", there is no recognition of it. "Should" is difficult to provide effective guidance for people's daily lives [41]. "When an actor feels that his or her important interests are inconsistent with social ethical requirements and even require him to make a major sacrifice, a natural question is: indeed, moral requirements are important. But why should I be moral?" [42] If there is no reasonable explanation of why "should" be made, this "should" is difficult to become the norm of daily life. The past ethics 
textbooks in our China often overlook the importance of moral reasoning. They just explained what should be done, instead of the reasons.

As a bridge to the ethics hall, ethics textbooks must proceed from the assumption of basic concepts, gradually demonstrate them and show the process of moral reasoning to students to enhance their moral reasoning ability. They should make students consciously use the ability to solve more ethical issues and return to the meaning of ethics as the "should be" [43].

\subsection{Insufficient Attention to Practice}

"In order to gain vitality, ethical theory must face real life, absorb theoretical nutrition from real life and return to real life to solve concrete moral problems" [44]. However, there are still obvious deficiencies in the connection of practice, mainly in the following two aspects:

Firstly, research method is out of touch. Some theoretical ideas are entirely made from the study. The point of views set by subjectivity often becomes the root of conceptual games and empty words in theoretical articles [45]. The construction of ethics textbooks should not only focus on the "the sky" of theory, but also strive to study the "site" of methods. They can gradually liberate from the metaphysical and transform the research paradigm. Then they will form a bottom-up comprehensive synthesis-analysis method [46] which is based on moral experience in real life. Hence, ethics can enter life and return to life [47].

Secondly, the case analysis ignores the domestic. At present, most of the cases in Chinese ethics textbooks are not based on the actual situation of the country or collect and excavate relevant examples of national conditions in our society. Instead, they use or copy the existing Western cases [48]. However, ethics, as a value discipline with great practicality in the social sciences, must be proceed from actual national conditions. We should pay attention to our society and think about major social realities to provide theoretical and rational value guidance for social development [49]. Hence, in the process of constructing ethics textbooks, we must fully tap domestic resources and pay attention to the collection and application of typical domestic cases.

\section{Conclusions}

After the beginning of the 1980s and the development stage of the 1990s, the ethics textbooks have been matured and improved gradually in the 21 st century. As an independent discipline, the development of ethics cannot be separated from the continuous improvement of teaching materials. Chinese ethics textbooks have experienced three stages of beginning, development and maturity since the reform and opening-up. In this process, we always adhere to the main theme and are guided by Marxism. The system is more mature and the structure is more reasonable. The object of ethics and its essence, the history of Chinese and foreign ethical thoughts, moral structure, applied ethics and ethical development prospects have been discussed in detail. But there is the space for further improvement in the form of expression, rationale, and practice of the textbook. In view of this, the construction of ethics textbooks must continue to adhere to the guidance of Marxism. And Chinese excellent traditional culture must be inherited with "compatibility and integration of diverse positions and methods" [50]. They should absorb the reasonable content of Western culture, innovate the expression of teaching materials, pay attention to theoretical logic deduction and focus on the reality of life. Then, ethics can enter into life and the acceptability, scientific and practicality of textbooks can be enhanced.

\section{References}

[1] Yang Yiqin, Professor Luo Guojie and Journal of Morality and Civilization, Morality and Civilization, (3), 2015.

[2] Wang Xiaoxi et al., 60 Years of Chinese Ethics, Shanghai People's Publishing House, (5), 2009.

[3] Wang Zeying, On the Comprehensive Innovation of the Construction of Ethics Teaching Material System of "Horse Engineering", Ethics Research, (6), 2012.

[4] Wan Junren, A New Theory of Ethics - Towards Modern Ethics, China Youth Publishing House, 241-242, 1994.

[5] Luo Guojie, Ethics, People's Publishing House, 2-3, 1989.

[6] Wang Xiaoxi and Guo Guangyin, General Theory of Ethics, China Radio and Television Press, 1, 1990.

[7] Zhang Yinghang, An Introduction to Ethics, Zhejiang University Press, 43, 2009.

[8] Wang Haiming, Principles of Ethics (Third Edition), Beijing University Press, 3,78,82, 2009.

[9] Liao Shenbai: An Introduction to Ethics, Beijing Normal University Press, 5,21, 2009

[10] Luo Guojie, Marxist Ethics, People's Publishing House, 4, 1982.

[11] Tang Kailin, Concise Marxist Ethics, Hubei People's Publishing House, 45, 1983.

[12] Xiao Xuehui, Principles of Ethics, Sichuan Academy of Social Sciences Press, 42, 1986.

[13] Wang Haiming, Principles of Ethics (Third Edition), Beijing University Press, 3,78,82, 2009.

[14] Liao Shenbai: An Introduction to Ethics, Beijing Normal University Press, 5,21, 2009

[15] "Ethics" Writing Group, Ethics, Higher Education Publishing House, People's Publishing House, 3, 56, 124-126, 2012.

[16] Wei Daolu et al., Ethics (Revised), Lujiang Publishing House, $33,39,1988$,

[17] Zhang Haishan, Concise Ethics, Sun Yat-sen University Press, $6,30,1986$

[18] Zhang Yinghang, An Introduction to Ethics, Zhejiang University Press, 43, 2009. 
[19] Bao Lianzong and Zhu Yiting, An Introduction to Ethics, Henan People's Publishing House, 23, 1985.

[20] Zhang Yinghang, An Introduction to Ethics, Zhejiang University Press, 43, 2009.

[21] "Ethics" Writing Group, Ethics, Higher Education Publishing House, People's Publishing House, 3, 56, 124-126, 2012.

[22] Wei Daolu et al., Ethics (Revised), Lujiang Publishing House, $33,39,1988$,

[23] Zhang Haishan, Concise Ethics, Sun Yat-sen University Press, $6,30,1986$

[24] Luo Guojie, Ethics, People's Publishing House, 2-3, 1989.

[25] "Ethics" Writing Group, Ethics, Higher Education Publishing House, People's Publishing House, 3, 56, 124-126, 2012.

[26] Tang Kailin, Concise Marxist Ethics, Hubei People's Publishing House, 45, 1983.

[27] Wang Haiming, Principles of Ethics (Third Edition), Beijing University Press, 3,78,82, 2009.

[28] Wang Zeying, Ethics, Beijing Normal University Press, 72-73, 325, 2012.

[29] Liao Shenbai: An Introduction to Ethics, Beijing Normal University Press, 5,21, 2009

[30] Wang Zeying, Ethics, Beijing Normal University Press, 72-73, $325,2012$.

[31] Zhou Zhongzhi, Ethics, People's Publishing House, 2004.

[32] Zhang Xiaoping, New Edition of Ethics, Sichuan University Press, 2011.

[33] Wang Xiaoxi, An Outline of Ethics, China Radio and Television Press, 296-308, 267 and 270, 1992.

[34] Yu Yaping at al., Ethics, Shanghai Jiaotong University Press, Chapter 13, 2002.

[35] Wang Zeying, Ethics, Beijing Normal University Press, 72-73, $325,2012$.

[36] Wei Yingmin, New Ethics Course (Third Edition), Peking University Press, 2012.
[37] Complete Works of Marx and Engels, Volume 1, People's Publishing House, 164, 1995.

[38] Wang Xiaoxi, An Outline of Ethics, China Radio and Television Press, 296-308, 267 and 270, 1992.

[39] Wang Xiaoxi, An Outline of Ethics, China Radio and Television Press, 296-308, 267 and 270, 1992.

[40] Li Peichao and Zhong Xijin, Paradigms and Validity: Value Prediction of Localization Construction of Chinese Environmental Ethics, Ethics Research, (6), 2013.

[41] Yang Zongyuan, "Reading the Reasons for Morality Causes Reflections on the Compilation of Ethics Textbooks", Journal of Renmin University of China, (4), 2009.

[42] People-oriented: Marxist Humanistic Dimension of the Relationship Between Subject and Object in Ideological and Political Education, Teaching and Research, (2), 2016.

[43] Wang Xiaoxi, Morality, Ethics, Should and Their Interrelations, Jianghai Journal, (2), 2004

[44] Luo Guojie, Review and Prospect of Chinese Ethics in the Past Ten Years (continued). Morality and Civilization, (2) 1991.

[45] Wang Xiaoxi, Where is Chinese Ethics Going? Jiangsu Social Sciences, (1), 1993.

[46] Wang Lulu, Research and Method of Chinese Local Ethics in the Period of Social Transition, Philosophical Research, (12), 2007.

[47] Wang Lulu, Between "Rite" and "Law"-In the Changes of Chinese Rural Society from the Perspective of Ethics "Order and Justice", Chinese Social Sciences, (7), 2015.

[48] Lv Yaohuai and Liu Zhifeng, A Probe into the Curriculum Reform of Applied Ethics Research, University Educational Science, (3), 2015.

[49] Ge Chenhong, Review and Prospect, Sixty Years of Ethics Theory and Practice, Morality and Civilization, (1), 2010.

[50] Wan Junren, Widening the Horizon of History and Culture: On Reasonable Inheritance of Chinese Excellent Traditional Culture Reflections, People's Daily, (16), 2015. 